\title{
Design of Touch Key-Voice Command Based Vehicle Additional Security System
}

\author{
Muhammad Firdaus Jauhari ${ }^{1, *}$ Rusmini Sri Maryati ${ }^{1}$, Raihan Raihan ${ }^{1}$ \\ ${ }^{1}$ Automotive Mechanical Engineering, Politeknik Negeri Banjarmasin \\ ${ }^{*}$ Corresponding author. Email: firdaus.jauhari@ poliban.ac.id
}

\begin{abstract}
Vehicle theft is still a big problem, usually by damaging the ignition switch. So that additional security is needed in a vehicle. The following paper describes a vehicle security system with a combination of a touch key and voice commands to be installed on a motorcycle. To prevent theft, a motorcycle can only be started by touching the hand at a secret point and using voice command with a predefined password. The proposed prototype uses an Arduino microcontroller, a touch key module, a Bluetooth module, and a relay module. The test results show that the security system that has been created successfully starts the engine only if it is activated using the touch key first. It will pass a voltage of $7.9 \mathrm{~V}$ to power the microcontroller. Then activate the CKP sensor and fuel injector using a voice command via a Bluetooth smartphone connection. The distance of sending data from the smartphone to the Bluetooth module in conditions without obstacles can reach 12 meters. Repeated testing shows the designed prototype can work well as expected. Therefore, this prototype has the potential to be developed and implemented as a vehicle security system.
\end{abstract}

Keywords: Vehicle, Theft, Security, Touch key, Voice command.

\section{INTRODUCTION}

A motorcycle theft crime is still the dominant crime in Indonesia. Throughout 2018, according to BPS data in the publication of 2019 criminal statistics, motorcycle theft was ranked second with 27,731 cases [1]. Vehicle theft is a worldwide problem, and the export market is a large part of organized vehicle theft syndicates. In the USA, vehicle theft is becoming a lucrative crime with total losses of up to $\$ 8.6$ billion per year [2]. Therefore, additional security is needed to ensure vehicle safety. Smartphones can be used as devices to create a security system on a vehicle. The design of a security system for taxis as public transportation using a microcontroller as an internet of things device was carried out by [3]. The design of vehicle safety utilizes Bluetooth technology which is configured with a microcontroller as a dual security device and is connected to a current source on the switch or ignition as described in the paper [4]. In another study, a vehicle safety system, without an additional switch, was presented, which works automatically after the ignition switch is turned off. The system is double layer security, namely activation of touch key and activation of Bluetooth signals to start the vehicle [5]. Another study proposes a vehicle security system that utilizes a microcontroller and android based
SMS media to control relays that are capable of disconnecting and connecting the current on a motorized vehicle CDI [6]. Next, there is an additional vehicle safety system that is activated by making the switch in a hidden place. If there is theft, the vehicle engine cannot be turned on and sounds an alarm. At the same time, the security system will send SMS and 3 phone calls to the owner's cellphone number [7]. Meanwhile, another paper made the design of a GPS-based motor vehicle security system and Bluetooth connection with emergency security features that are accurate and precise to support interactive security systems [8]. The use of a microcontroller is very wide and varies even for vehicle safety due to negligence while driving as described in the paper [9].

For the design presented in this paper, a vehicle additional security system with a combination of touch key and voice command via smartphone is proposed to the security system installed. The two sub-systems in the vehicle, namely the CKP sensor signal and the signal entering the fuel injector are locked by a security module, so the vehicle cannot be started. To start the vehicle, after the ignition switch is on, the smartphone must be connected to a security system via Bluetooth. Then use a password via the voice command feature to normalize the CKP sensor signal and the fuel injector 
signal, after which the new vehicle can start. It is hoped that this can prevent the crime of vehicle theft by forcibly breaking the ignition switch.

\section{METHODS}

Figure 1 is a Control flow of the proposed system which shows the layout of our project which gives an overview of what we are going to do in the system. The components used in our project are - Arduino Uno, Bluetooth module, Smartphone, Relay module, and Touch key module as shown in Figure 2. Arduino Uno is a microcontroller board that is fully controlled by the ATmega328. The Arduino Uno has 14 digital input or output pins, 6 analog inputs, a $16 \mathrm{MHz}$ crystal oscillator, a USB connection, a power jack, an ICSP header, and a reset button [10]. The Arduino Uno board is also supported by the Arduino IDE (Integrated Development Environment) software. In the Arduino IDE software, there is a kind of black message box that functions to display status, such as error messages, compile, and upload programs. At the bottom right side shows the board that is configured and the COM Ports used. The embedded code is developed in a short period because IDE contains inbuilt libraries [11].

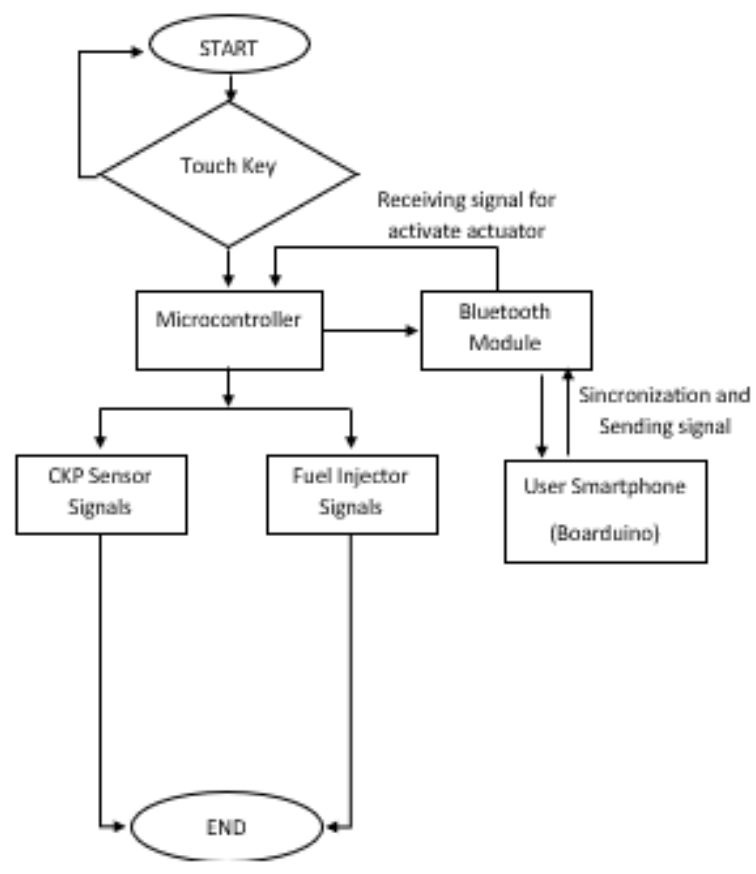

Figure 1 Control flow of the proposed system.

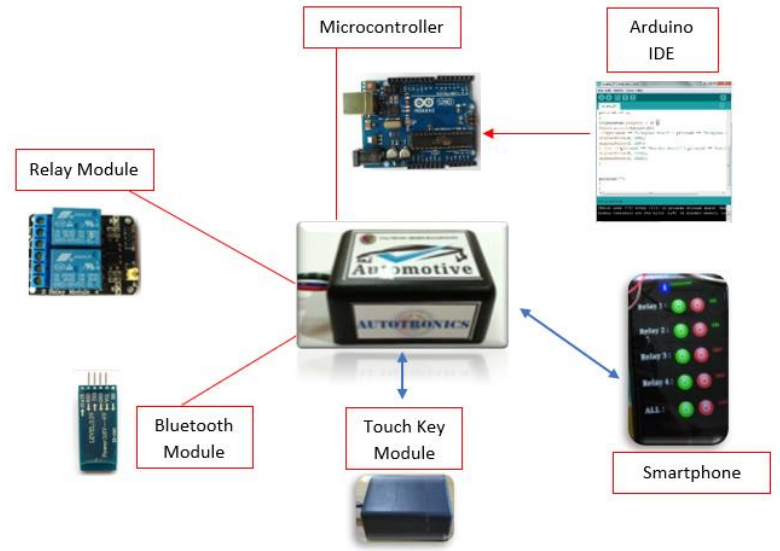

Figure 2 Embedded system architecture.

The system proposed in this paper is implemented on a motorcycle. Embedded system architecture as shown in Figure 2, all components are packed in one box. Not only as a place to store system components, but this box also functions to protect the system from collisions and wetting from liquids. The hardware system consists of three main components, namely a microcontroller, a Bluetooth module, and a relay module. The power of the device is supplied via the touch key module, which activates with the touch of a hand. The system software is the Arduino IDE which programs the microcontroller using $\mathrm{C}++$ language. The security system embedded in the motorcycle is controlled using a smartphone connected via Bluetooth media.

\subsection{Design of Tools and Systems}

At this stage, a comprehensive security system design is carried out. The system design can be seen in the following flow chart (Figure 3). Starting from the system concept, then a system model design is made which is equipped with the required component specifications. If all of these have been met, the system is built and tested to ensure the system can work according to the specified design.

The design of this safety system can be applied to all vehicles, especially those that use injection technology, for older vehicles with this type of carburetor a little adjustment is needed. The main components of the safety system that will be installed on the motorcycle as shown in figure 4, consist of a smartphone, HC-05 bluetooth module, Arduino Uno microcontroller, and a relay module. The previous Boarduino application needed to be installed on a smartphone to be able to make a Bluetooth connection with the vehicle, this connection procedure is required to start the vehicle. 


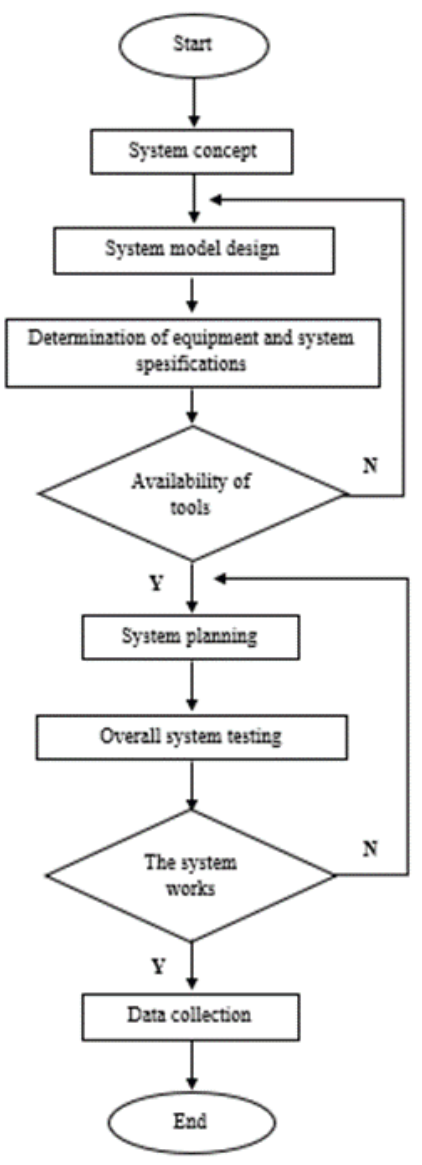

Figure 3 System design flow chart.

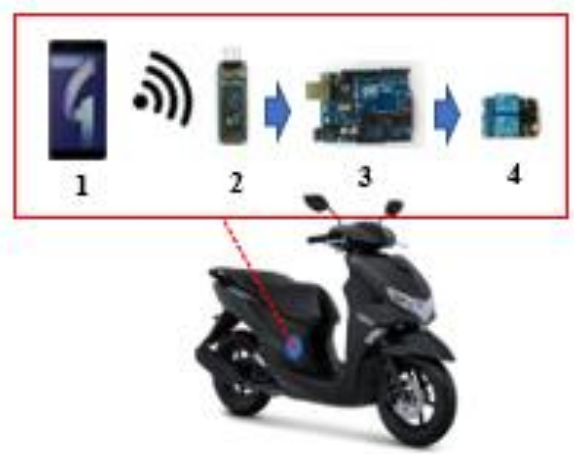

Figure 4 System design flow chart.

Description :

1. Smartphone

2. HC-05 Bluetooth module

3. Arduino Uno microcontroller

4. Relay module

In this system design, the vehicle owner's smartphone will connect to the microcontroller via a Bluetooth connection. Once connected, voice commands are used to activate the CKP sensor signal and the fuel injector signal through the relay module. After the two normal signals return, the new vehicle can be started as usual. The design of this security system is divided into two stages, namely designing hardware and designing applications on smartphones.

\section{Hardware Design}

Hardware design plays a role in sending input from a smartphone via a Bluetooth connection and received by the Bluetooth Module. The data received will be forwarded to the Arduino Uno microcontroller to reactivate the CKP sensor signal and the fuel injector. The connection between the Arduino Uno and the Bluetooth Module is via the TX (Transferring Pin) and RX (Receiving Pin) pins on both devices (Figure 5).

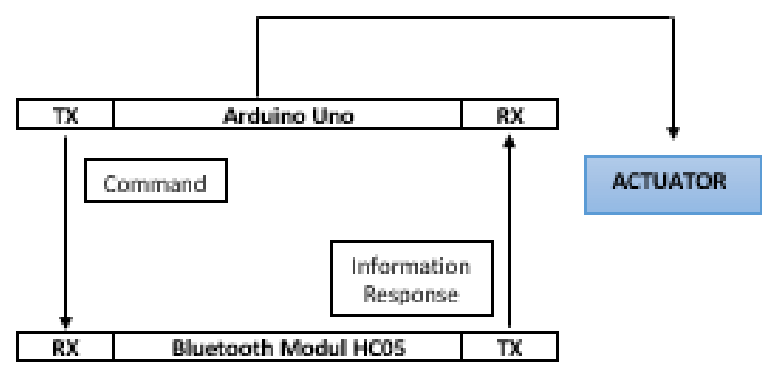

Figure 5 Arduino microcontroller and bluetooth module.

\section{Software Design}

The software design is in the form of a smartphone application that can communicate with the Arduino Uno microcontroller embedded in the vehicle system. Communication utilizes Bluetooth which is available on both devices, and the application is made with the display of the "Push, Voice, and Text" buttons as shown in Figure 6. In this proposed project the "Talk to Your Arduino" feature is used to activate relay 1 and relay 2 connected to the CKP sensor and fuel injectors on the vehicle. The flow chart of smartphone software design can be seen in Figure 7.

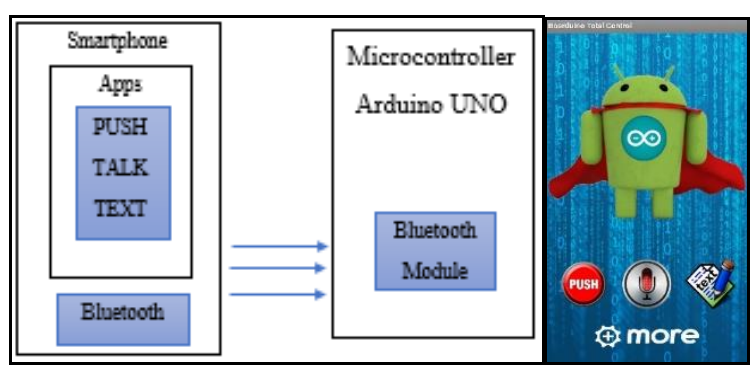

Figure 6 Block diagram of software design.

Testing of tools and systems is carried out in stages for the Touch key module, Arduino Uno Microcontroller, Bluetooth module, and Relay module using the Arduino IDE software, and results are obtained that the system is working properly. Tests are carried out in the laboratory and 
the field in conditions that are relevant to the actual situation

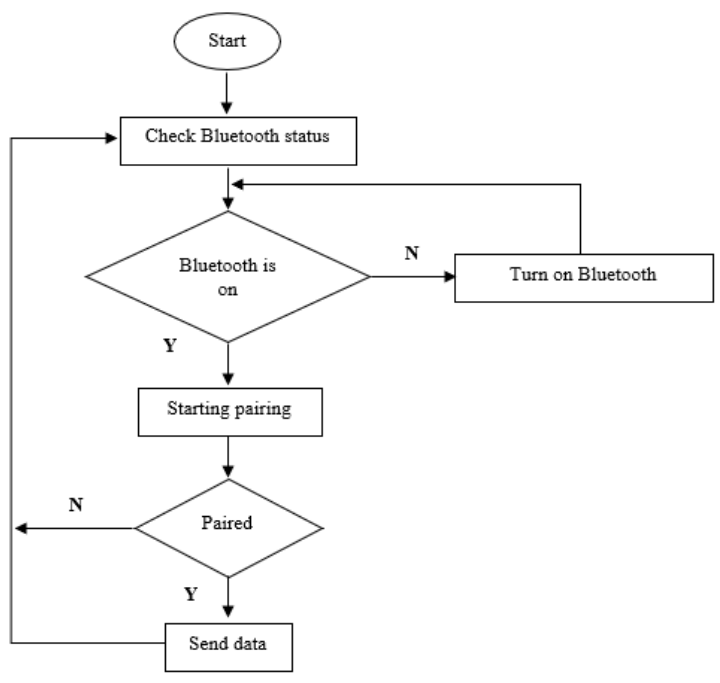

Figure 7 Smartphone application flow chart

In the flowchart above, it can be seen that the boarduino application uses a bluetooth connection that is activated by a smartphone and a bluetooth module on the security system device. If the two devices are paired, a command will be sent from the smartphone to activate the actuators in the security system module.

\section{RESULTS AND DISCUSSION}

Figure 8 shows a block diagram of the vehicle security system being developed. In the initial conditions, the CKP sensor signal and the fuel injector signal leading to the vehicle's ECM (Engine Control Module) will be deflected when the ignition switch is off. So, even if the ignition switch is on, the vehicle cannot be turned on without opening the locked signal. In a vehicle, the CKP sensor signal is the main information that states the vehicle engine is running. Meanwhile, the fuel injector signal is an electric current that activates the injection of fuel into the combustion chamber, so that without these two signals the vehicle will not be able to run. The relay module is used as an actuator for the proposed security system, the system will activate with a Bluetooth connection between the microcontroller and smartphone, then a voice command is required to unlock the signal so that the vehicle can start. The process is that when the vehicle is turned on, it is necessary to activate the touch of the hand at the secret point of the vehicle. The touch key module acts as the first security, which will continue the electric current from the battery and activate the control unit (microcontroller). Because the control unit works in a voltage range of $5-9 \mathrm{~V}$, a step down is used to supply $7.8 \mathrm{~V}$ of power to the control unit, then the HC-05 Bluetooth module will send a signal to the vehicle user's smartphone to pair the Bluetooth connection with the specified password. For safety reasons, a voltage regulator performance test was carried out which transmits electric current from the battery to the microcontroller. The microcontroller power supply voltage should not exceed $9 \mathrm{~V}$, because overheating will damage the components. For this purpose, measurements are made using a multimeter on the hardware mounted on the motorcycle. The voltage measurement results are shown in Table 1.

Table 1 Voltage Measurement

\begin{tabular}{|c|c|}
\hline \multicolumn{2}{|c|}{ Measurement } \\
\hline $\begin{array}{c}\text { Vin (before stepped } \\
\text { down) }\end{array}$ & $\begin{array}{c}\text { Vout (after stepped } \\
\text { down) }\end{array}$ \\
\hline $12.7 \mathrm{~V}$ & $7.8 \mathrm{~V}$ \\
\hline
\end{tabular}

When the Bluetooth connection between devices is connected, the user will send a signal using a smartphone using a voice command in the form of a password "hidupkan motor" as shown in Figure 9. The signal received by the Bluetooth module will be forwarded to Arduino Uno to provide current to the actuator coil, then the current will activate the CKP Sensor signal and the Fuel Injector signal. Until this stage the vehicle is ready for use, the user can press the starter switch button and start the vehicle.

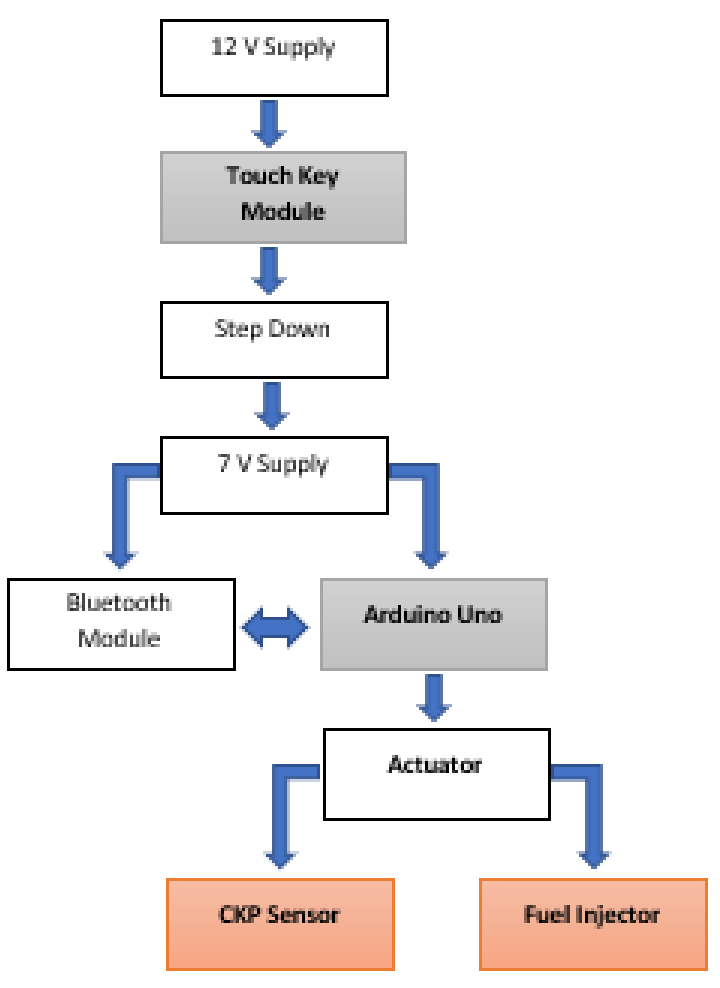

Figure 8 Block diagram of proposed system. 


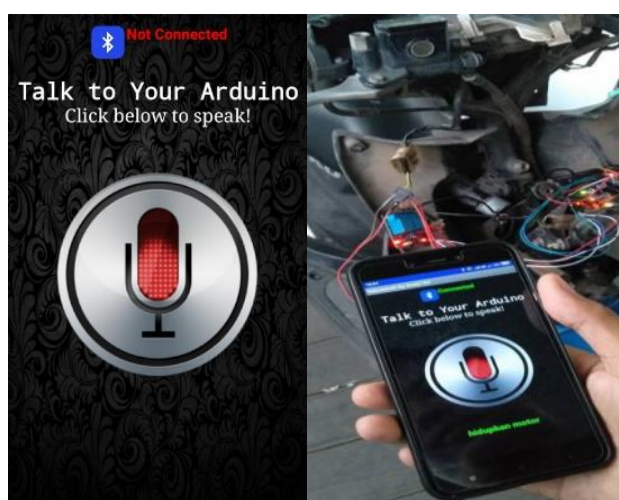

Figure 9 The user's smartphone sends a signal

When doing the test, the device connection between the Bluetooth Module and the smartphone should not be disconnected. Table 2 shows the data transmission distance from the smartphone to the Bluetooth module in unhindered conditions which can reach 12 meters.

Table 2. Security system test results

\begin{tabular}{c|c|c}
\hline No & Bluetooth distance & Data sent \\
\hline 1 & 3 meter & Sent \\
\hline 2 & 6 meter & Sent \\
\hline 3 & 9 meter & Sent \\
\hline 4 & 12 meter & Sent \\
\hline 5 & 15 meter & Not sent \\
\hline
\end{tabular}

\section{CONCLUSION}

The design of an additional vehicle security system is implemented to prevent the crime of motor vehicle theft. The security system created is a combination of touch key and voice commands using an Arduino microcontroller as the control unit. The security system starts to work when the vehicle is turned off, and to turn it on requires touch activation at a secret point on the vehicle as a first step. Next, make a Bluetooth connection between the vehicle and the smartphone to send voice commands so that it can forward the CKP sensor signal and the fuel injector signal to the previously locked ECM. The proposed security system has been tested and gives the expected results.

\section{ACKNOWLEDGMENTS}

We would like to thank P3M of Politeknik Negeri Banjarmasin for the incentive support for the publication of this paper, as well as colleagues and students of the Department of Automotive Mechanical Engineering who have assisted in the suggestions and work of this project.

\section{REFERENCES}

[1] BPS, “Statistik Kriminal 2019," 2019, doi: 04330.1903.
[2] H. Bila and C. Roelfose, "Organised Vehicle Theft Operations: Unravelling the Matrix," Intern. Secur., vol. 8, no. 2, pp. 31-50, 2016, doi: 10.5604/01.3001.0010.2269.

[3] I. Indrianto, M. N. I. Susanti, R. R. A. Siregar, P. P. J., and Y. Purwanto, "Smart taxi security system design with internet of things (IoT),"

TELKOMNIKA (Telecommunication Comput. Electron. Control., vol. 17, no. 3, p. 1250, 2019, doi: 10.12928/telkomnika.v17i3.10167.

[4] Z. Muttaqin, D. Kisbianty, M. I. Bustami, P. Studi, and S. Komputer, "PERANCANGAN SISTEM KEAMANAN SEPEDA MOTOR MENGGUNAKAN BLUETOOTH,” J. Ilm. Media Process., vol. 10, no. 2, pp. 1-11, 2015.

[5] M. M. A. M F Jauhari, "The development of appropriate technology : Simple double layer vehicle safety system,” J. Phys. Conf. Ser., vol. 1450, p. 012103, 2020, doi: 10.1088/17426596/1450/1/012103.

[6] T. Ardiansyah, Beni Irawan, Rismawan, "Rancang bangun sistem keamanan kendaraan bermotor dengan sms gateway berbasis mikrokontroler dan android [1] [2] [3]," Coding, Sist. Komput. Untan, vol. 03, no. 1, pp. 11-19, 2015.

[7] R. R. Rachmat and E. S. Julian, "PENGAMAN SEPEDA MOTOR BERBASIS MIKROKONTROLER," JETri, vol. 13, no. 2, pp. 1-10, 2016.

[8] O. K. Saputra and Herlinawati, "Rancang Bangun Sistem Keamanan Kendaraan Bermotor Berbasis GPS ( Global Positioning System ) dan Koneksi Bluetooth," Rekayasa dan Teknol. Elektro, vol. 11, no. 3, p. 9, 2017.

[9] L. P. Gîlcă Gheorghe, “AUTOMATIC SAFETY VEHICLE CONTROL BASED ON ARDUINO MICROCONTROLLER,” Eng. Ser., no. 4, 2017.

[10] A. Kadir, Pemrograman Arduino dan Processing, 1st ed. Elex Media Komputindo, 2017.

[11] N. Batra and N. K. Batra, "Automated Power Window Opening on Carbon Monoxide Detection," Int. J. Veh. Struct. Syst., vol. 10, no. 3, pp. 179183, 2018, doi: 10.4273/ijvss.10.3.05. 